Neuer Männerkatheter

Äußerst anpassungsfähig

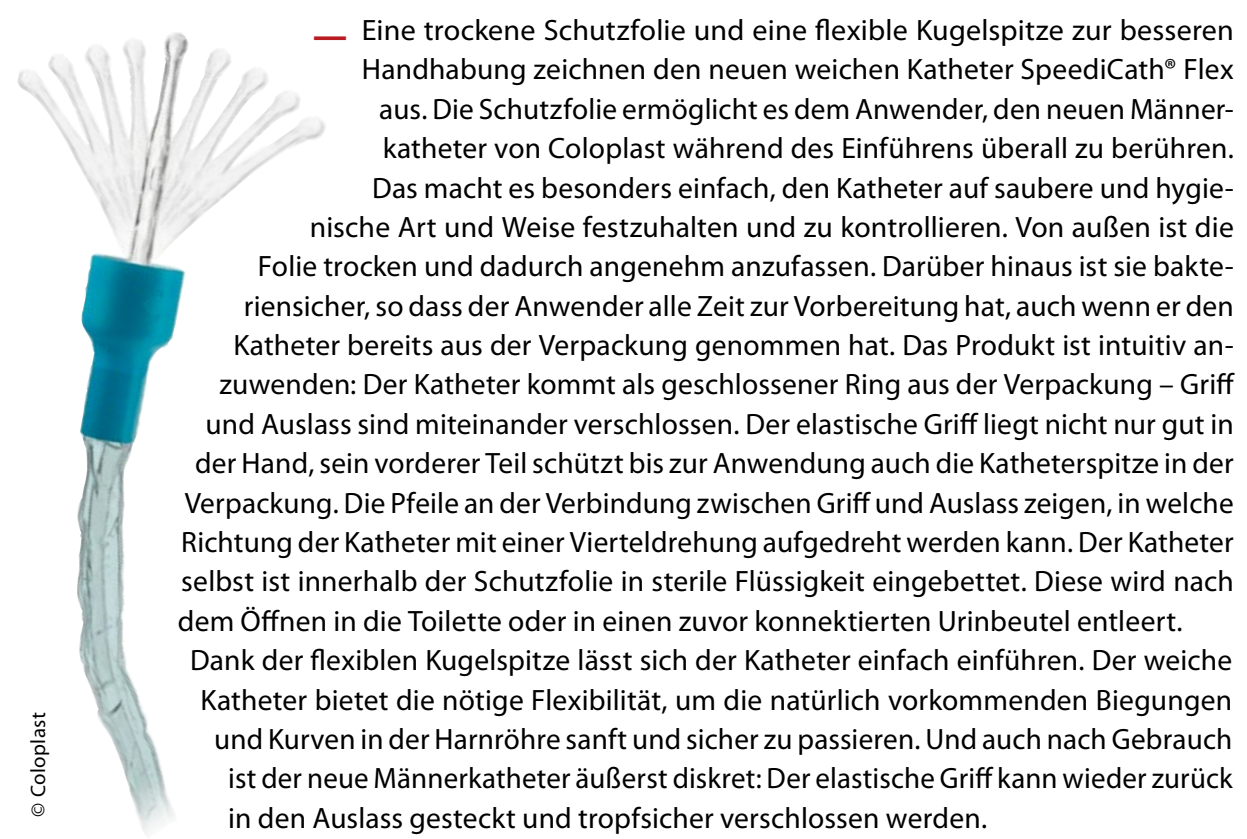

www.flex.coloplast.de
Auszeichnung

\section{Pain Care Award 2016 geht nach Hannover}

_ Zum vierten Mal hat der Schmerzspezialist Mundipharma den Pain Care Award (ehemals "Pain Nurse des Jahres") für außerordentliche Leistungen in der Betreuung von Patienten mit Schmerzen verliehen. Bei dem diesjährigen Gewinner-Projekt "Akutschmerzdienst" von Tamara Kasten, DIAKOVERE Henriettenstift gGmbH Hannover, geht es um die Schmerzversorgung von Sectio-Patientinnen. Das Projekt hob sich mit seinem akribischen Qualitätsmanagement, das Fragebögen, Schmerzdokumentationen, Ziel- und Maßnahmenpläne sowie Informationsflyer in interdisziplinärer Zusammenarbeit umfasst hervor. Die Vielzahl an Einreichungen in diesem Jahr zeige ein qualitativ sehr hohes Level, so Prof. Dr. Jürgen Osterbrink vom wissenschaftlichen Beirat.

www.mundipharma.de
App Unterstützung Bedarfsgerechte Ernährungstherapie

— Die Umsetzung einer bedarfsgerechten Ernährung unter Berücksichtigung verschiedener Nährsubstrate bei individuell variierendem Bedarf und unterschiedlicher Applikationsdauer ist besonders bei schwerkranken Patienten häufig sehr Komplex. Schnell besteht das Risiko, den Patienten zu viel oder zu wenig Energie bzw. Protein anzubieten. Die KabilnfusionsPlaner App erlaubt die Planung der Ernährungstherapie und die Dokumentation der tatsächlich umgesetzten enteralen, parenteralen bzw. sonstigen Ernährungstherapien. Es können die auf der Station verfügbaren Produkte unterschiedlicher Hersteller eingegeben werden. So kann selbst bei häufig wechselnden Ernährungstherapien der Überblick über die erreichte Energie- und Proteinzufuhr im Verlauf der Behandlung behalten werden.

www.fresenius-kabi.de

Nützliches Tool

\title{
Kostenloser Pflegegradrechner
}

— Mit der Einführung des Zweiten Pflegestärkungsgesetzes werden zum 01.01.2017 die bisher geltenden Pflegestufen auf Pflegegrade gemäß des Neuen Begutachtungsassessments (NBA) umgestellt. Zur leichteren Berechnung stellt der Bremer Softwaredienstleister und Pflegespezialist atacama Software ab sofort einen kostenfrei nutzbaren Online-Rechner zur Verfügung. Mithilfe des NBA werden die individuellen

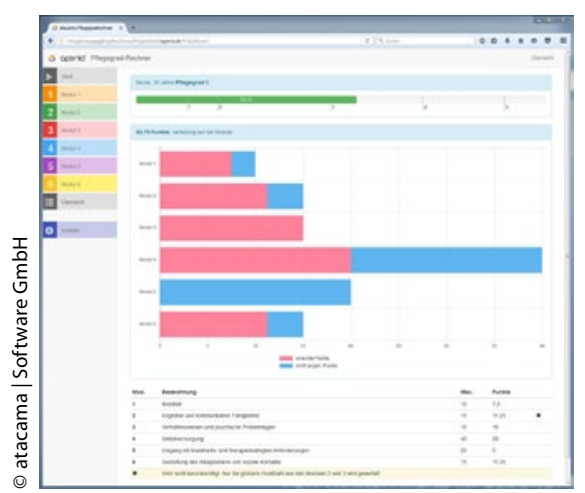

Beeinträchtigungen und Fähigkeiten der Pflegebedürftigen erfasst und bewertet. Anhand von sechs Kategorien, die unterschiedliche Lebensbereiche widerspiegeln, wird mit dem NBA der Grad der Selbstständigkeit der pflegebedürftigen Personen eingeschätzt. Der apenio Pflegegradrechner ermöglicht sowohl hauptberuflich Pflegenden als auch pflegenden Angehörigen die schnelle und einfache Ermittlung des Pflegegrades. Der komfortable OnlineRechner umfasst alle im NBA vorgesehenen Kategorien und gibt einen umfassenden Überblick über die gesamtmögliche sowie die bisher erreichte Punktzahl für jeden dieser Bereiche. Zusatzfunktionen wie das Wiederaufnehmen einer zuvor begonnenen Pflegegradberechnung machen den Browser-basierten Pflegegradrechner zu einem hilfreichen Tool für Pflegekräfte sowohl in Pflegeeinrichtungen als auch im häuslichen Umfeld.

www.apenio.de/pflegegradrechner 